\title{
Effect of Heating Rate on the Formation of Intermetallics during SHS Process
}

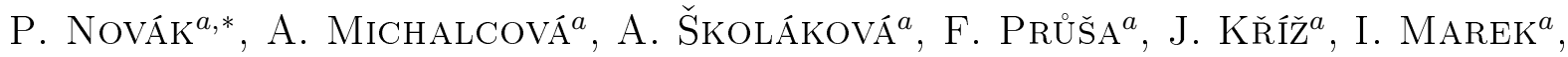 \\ T.F. Kubatík ${ }^{b}$, M. KARLÍK ${ }^{c}$, P. HAUŠILD ${ }^{c}$ AND J. KOPEČEK ${ }^{d}$ \\ ${ }^{a}$ Institute of Chemical Technology, Prague, Department of Metals and Corrosion Engineering, \\ Technická 5, 16628 Prague 6, Czech Republic \\ ${ }^{b}$ Institute of Plasma Physics AS CR, v.v.i., Za Slovankou 1782/3, 18200 Prague 8, Czech Republic \\ ${ }^{c}$ Czech Technical University in Prague, Faculty of Nuclear Sciences and Physical Engineering, \\ Department of Materials, Trojanova 13, 12000 Prague 2, Czech Republic \\ ${ }^{d}$ Institute of Physics of the ASCR, v.v.i., Na Slovance 2, 18221 Prague 8, Czech Republic
}

\begin{abstract}
Self-propagating high-temperature synthesis is a simple and efficient method for the synthesis of various compounds including ceramics and intermetallics. In this process, the compressed mixture of elemental or master alloy powders is ignited or heated to initiate the exothermic reactions leading to the formation of desired compounds. In order to control the process efficiently, the effect of several important parameters has to be determined in each applied alloy system. Previous results showed that those parameters are: initiation temperature, process duration, pressure used for compression and heating rate. This paper is devoted to the description and explanation of the effect of the heating rate on the formation of intermetallics during self-propagating high-temperature synthesis in $\mathrm{Fe}-\mathrm{Al}$ and $\mathrm{Ni}-\mathrm{Ti}$ systems. Differential thermal analysis of compressed powder mixtures under various heating conditions and microstructure observation of samples prepared by various heating rates using electric resistance heating and spark plasma sintering were carried out. The effect of heating rates on the formations of intermetallics in studied systems is discussed in this paper.
\end{abstract}

DOI: 10.12693 /APhysPolA.128.561

PACS: 61.66.Dk, 65.40.-b, 61.05.cp

\section{Introduction}

Reaction synthesis has been established as an alternative route of the synthesis of intermetallics. Due to highly exothermal nature of the reactions between elemental powders, the reactions produce enormous heat that sustains and supports the propagation of the reactions. Therefore, the process is called self-propagating high-temperature synthesis (SHS) [1]. To control the process efficiently, the effect of process conditions on the SHS progress and product structure has to be described in each particular system. However, some dependences seem to be general. In our previous works it has been found that the microstructure and porosity is positively affected by the increase of the heating rate in both $\mathrm{Fe}-\mathrm{Al}-$ $\mathrm{Si}$ and $\mathrm{Ti}-\mathrm{Al}-\mathrm{Si}$ systems $[2,3]$. The set of SHS parameters leading to homogeneous low-porosity $\mathrm{Ti}-\mathrm{Al}-\mathrm{Si}$ alloys is protected by Czech patent [4]. In present paper, the effect of heating rate on the SHS process was described on two binary systems: $\mathrm{Fe}-\mathrm{Al}$ and $\mathrm{Ni}-\mathrm{Ti}$. The reason for choice of these systems lies in the presence of melt during the initiation of the reactions. In $\mathrm{Fe}-\mathrm{Al}$ system, the formation of the melt before initiation was found by in situ X-ray diffraction (XRD) in our previous paper [5], while in $\mathrm{Ni}-\mathrm{Ti}$ system the reactions initiate in solid state.

* corresponding author; e-mail: panovak@vscht.cz

\section{Experimental}

The effect of heating rate was investigated on green bodies of cylindrical shape of $10 \mathrm{~mm}$ in diameter and approximately $10 \mathrm{~mm}$ in height. Green bodies were prepared by blending of the iron and aluminium or nickel and titanium powders $(<100 \mathrm{~mm},>99.8 \%$ purity $)$ and pressing using LabTest 5.250SP1-VM universal loading machine using a pressure of $640 \mathrm{MPa}$.

To describe the effect of the heating rate, the differential thermal analysis (DTA) was carried out using Setaram Setsys Evolution 1750 device at the heating rates of $2-30 \mathrm{~K} \mathrm{~min}{ }^{-1}$. Due to the limitations of the DTA apparatus, the investigation of higher heating rates was carried out by rapid heating of the sample in preheated electric resistance furnace and simultaneous recording of the temperature profile by optical pyrometer (Optris OPTP20-2M).

SHS processing of FeAl25 and NiTi46 (in wt\%) green bodies (compressed powder mixtures) was carried out at $900{ }^{\circ} \mathrm{C}$ with the heating rates equivalent to the conditions of thermal analysis. Spark plasma sintering (SPS) of the same compositions of powder mixtures was also tested to achieve high heating rate $(300 \mathrm{~K} / \mathrm{min})$. SPS was carried out in the Institute of Plasma Physics AS CR using Thermal Technology SPS 10-4 device (pressure $80 \mathrm{MPa}, 900^{\circ} \mathrm{C}, 20 \mathrm{~min}, 300 \mathrm{~K} / \mathrm{min}$ ). Microstructure of the prepared materials was observed by Olympus PME3 light microscope. AxioVision 4.7 and ImageJ $1.48 \mathrm{v}$ programs were applied for the digital image recording and 
processing. Phase composition was determined by XRD analysis using a PANalytical X'Pert diffractometer and by TESCAN VEGA 3 LMU scanning electron microscope equipped with Oxford Instruments X-max $20 \mathrm{~mm}^{2}$ SDD EDS analyser.

\section{Results \\ 3.1. Ni-Ti system}

In $\mathrm{Ni}-\mathrm{Ti}$ system, the DTA revealed two significant exothermic peaks (Fig. 1) when the heating rates of 10$30 \mathrm{~K} \mathrm{~min} \min ^{-1}$ were applied. With increasing heating rate, the second peak becomes to be more intensive and at $30 \mathrm{~K} / \mathrm{min}$ the first peak is nearly negligible. The positions of the exothermic peaks move to higher temperatures with the heating rate. The maximum of the first peak is observed at 471 and $504{ }^{\circ} \mathrm{C}$ at 10 and $30 \mathrm{~K} / \mathrm{min}$, respectively. The second peak has the maxima at $632{ }^{\circ} \mathrm{C}$ at $10 \mathrm{~K} / \mathrm{min}$ and at $669{ }^{\circ} \mathrm{C}$ at $30 \mathrm{~K} / \mathrm{min} \mathrm{XRD}$ analysis of the samples annealed at the temperatures close to the maxima of the exothermal peaks $\left(500\right.$ and $650{ }^{\circ} \mathrm{C}$ ) revealed that the first peak is associated with the formation of $\mathrm{Ti}_{2} \mathrm{Ni}$ phase, while the second one is related to the reaction of $\mathrm{Ti}_{2} \mathrm{Ni}$ phase with nickel, producing a mixture of $\mathrm{NiTi}$ and $\mathrm{Ni}_{3} \mathrm{Ti}$ phases (Fig. 1). When the heating rate of $2 \mathrm{~K}$ min $_{-1}$ was used in DTA, the thermal effects are almost negligible.

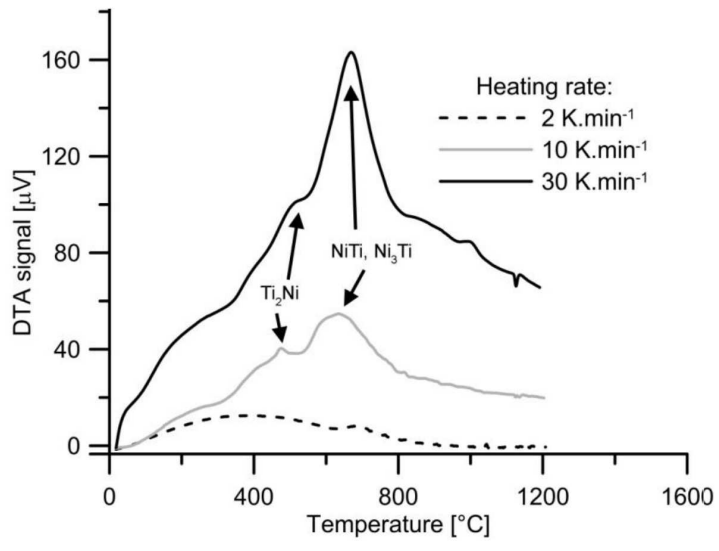

Fig. 1. DTA heating curves of Ni-Ti powder mixture in dependence on the heating rate.

Since our previous research revealed that extremely high heating rates are required in several systems (NiAl, $\mathrm{Ti}-\mathrm{Al}-\mathrm{Si}, \mathrm{Fe}-\mathrm{Al}-\mathrm{Si}$ ), the thermal analysis has to be also carried out with the heating rate of at least $300 \mathrm{~K} \mathrm{~min}^{-1}$. However, such analysis is impossible using DTA due to the limitations of the analytical devices. For this reason, the thermal analysis was also carried out by the use of the pyrometer on the sample placed in hot furnace. This analysis revealed two strong exothermic peaks and one weak thermal effect before them (Fig. 2). Those exothermic reactions are initiated at approximately $890^{\circ} \mathrm{C}$. It confirms our previous results presenting that no intermetallics are formed at $700-800^{\circ} \mathrm{C}$ in $\mathrm{Ni}-\mathrm{Ti}$ system, when the heating rate above $300 \mathrm{~K} \mathrm{~min}^{-1}$

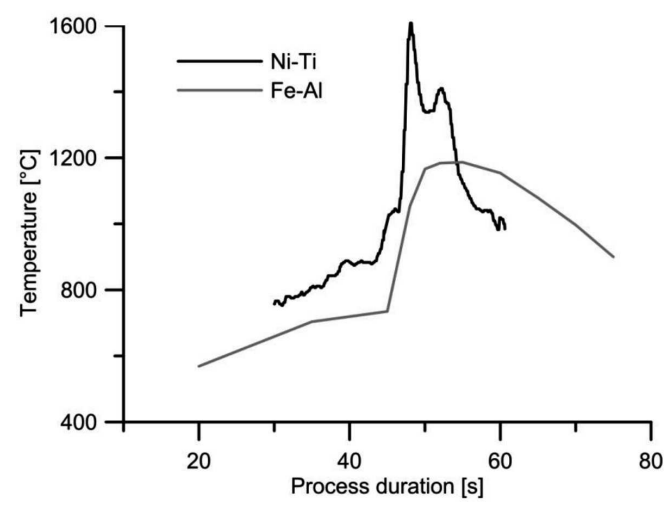

Fig. 2. Temperature profile of $\mathrm{Ni}+\mathrm{Ti}$ and $\mathrm{Fe}+\mathrm{Al}$ reactions with the heating rate of approximately $300 \mathrm{~K} / \mathrm{min}$ (recorded by pyrometer).

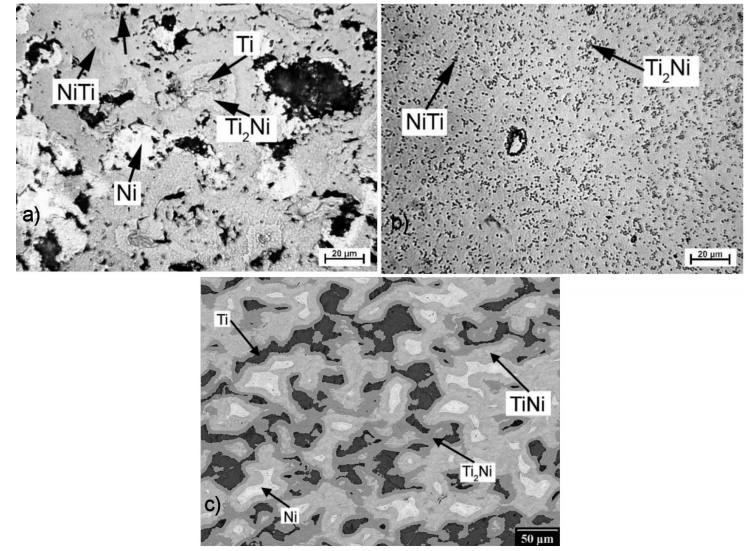

Fig. 3. Microstructure of Ni-Ti alloy obtained by SHS at $900{ }^{\circ} \mathrm{C}$ with the heating rate of (a) $20 \mathrm{~K} \mathrm{~min}^{-1}$, (b) approximately $300 \mathrm{~K} \mathrm{~min} \min ^{-1}$, (c) $300 \mathrm{~K} \mathrm{~min}^{-1}$ achieved by SPS.

was applied [6]. To describe these reactions exactly, the in situ XRD analysis is currently carried out.

Microstructure observation of the $\mathrm{Ni}-\mathrm{Ti}$ samples produced using the heating rates of 20 and $300 \mathrm{~K} \mathrm{~min}^{-1}$ is displayed in Fig. 3. It clearly presents that the increase of the heating rate improves the product homogeneity and reduces the porosity. When low heating rate was applied, the product is composed of the unreacted titanium and nickel particles surrounded by the layers of various $\mathrm{Ni}-$ Ti intermetallics $\left(\mathrm{Ti}_{2} \mathrm{Ni}, \mathrm{NiTi}\right.$ and $\left.\mathrm{Ni}_{3} \mathrm{Ti}\right)$. The porosity reduces from $30-40$ vol. $\%$ to less than 10 vol.\% when the heating rate increased from 20 to $300 \mathrm{~K} \mathrm{~min}^{-1}$. SPS was also applied to achieve the heating rate of $300 \mathrm{~K} \mathrm{~min}^{-1}$. The microstructure of the sample heated by SPS (Fig. 3c) is completely different from the sample initiated in hot electric resistance furnace (Fig. $3 \mathrm{~b}$ ). The structure of the SPS initiated sample comprises unreacted titanium and nickel areas, covered by the layers of $\mathrm{Ni}-\mathrm{Ti}$ intermetallics. The reason of such behaviour probably lies in the fact that in SPS, the highest heating rate is achieved on the surface of the particles due to the electric discharge between them [7]. In this area, the $\mathrm{Ni}-\mathrm{Ti}$ intermetallics 
form readily, thus acting as a diffusion barrier between the nickel and titanium particles and preventing the reaction propagation. Even though the porosity of the SPS material is below 1 vol.\%, the material is inapplicable. In conventional electric resistance heating, the sample is heated more uniformly, resulting in more homogeneous structure (Fig. 3b).

\section{2. $\mathrm{Fe}-\mathrm{Al}$ system}

The second investigated system was $\mathrm{Fe}-\mathrm{Al}$. DTA analysis revealed one exothermic effect occurring around the melting temperature of aluminium $\left(660^{\circ} \mathrm{C}\right)$. The position of this peak slightly moves to higher temperatures with increasing heating rate (Fig. 4). When the heating rates of $2-30 \mathrm{~K} \mathrm{~min}^{-1}$ are applied, the reactions are initiated below the melting point of aluminium. These reactions lead to the formation of $\mathrm{Fe}_{2} \mathrm{Al}_{5}$ and $\mathrm{FeAl}_{2}$ phases. These phases continuously transform to FeAl ordered phase when the temperature increases, as previously proved by in situ XRD [5]. On the other hand, at high heating rates aluminium melts preferentially. After that, the $\mathrm{Al}+\mathrm{Fe}$ reactions proceed between solid iron particle and molten aluminium. It can be derived from the temperature profile in Fig. 2, which shows that the reactions are initiated at the temperature over $700{ }^{\circ} \mathrm{C}$. This change of the mechanism was also confirmed by in situ XRD analysis in our previous paper [5].

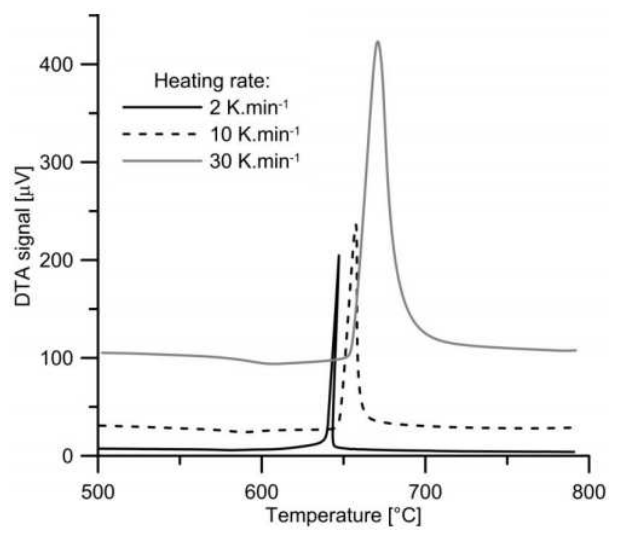

Fig. 4. DTA heating curves of $\mathrm{Fe}-\mathrm{Al}$ powder mixture in dependence on the heating rate.

Microstructure variations of the FeAl25 alloy with the heating rate are displayed in Fig. 5. It shows the same trend as in the case of $\mathrm{Ni}-\mathrm{Ti}$ powder mixtures (Fig. 3). Low heating rate results in the presence of unreacted iron and low amount of intermetallics. The increase of the heating rate nearly eliminates unreacted iron (Fig. 5b). The use of SPS was also found to have detrimental effect on SHS process, leading to the structure composed of large amount of unreacted iron and smaller amounts of intermetallics.

\section{Conclusion}

In this work, the effect of the heating rate on the formation of intermetallics during SHS process was studied

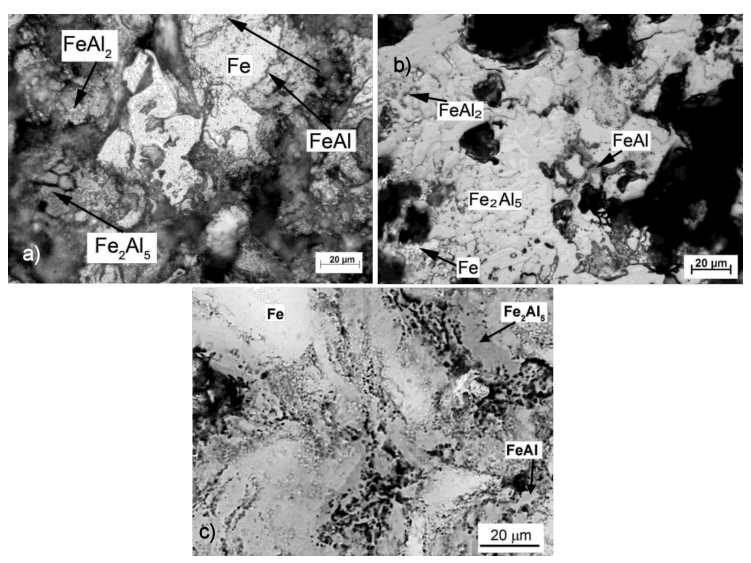

Fig. 5. Microstructure of $\mathrm{Fe}-\mathrm{Al}$ alloy obtained by SHS at $900{ }^{\circ} \mathrm{C}$ with the heating rate of (a) $20 \mathrm{~K} \mathrm{~min}^{-1}$, (b) approximately $300 \mathrm{~K} \min ^{-1}$, (c) $300 \mathrm{~K} \min ^{-1}$ achieved by SPS.

in $\mathrm{Ni}-\mathrm{Ti}$ and $\mathrm{Fe}-\mathrm{Al}$ systems. In both alloy systems, the same dependences were observed:

- The increase of the heating rate moves the exothermic effects to higher initiation and peak temperatures.

- Higher heating rate results in minimization of the amount of unreacted initial elements and lowering the porosity.

- SPS is not suitable as the initiation source for SHS.

Observed dependences are also in agreement with previous investigations carried out in $\mathrm{Ti}-\mathrm{Al}-\mathrm{Si}$ and $\mathrm{Fe}-\mathrm{Al}-\mathrm{Si}$ systems. It can be expected that the presented results have general validity for SHS synthesis of intermetallics.

\section{Acknowledgments}

This research was supported by the Czech Science Foundation, project 14-03044S.

\section{References}

[1] J. Barbosa, C. Silva Ribeiro, A. Caetano Monteiro, Intermetallics 15, 945 (2007).

[2] P. Novák, A. Michalcová, M. Voděrová, M. Šíma, J. Šerák, D. Vojtěch, K. Wienerová, J. Alloys Comp. 493, 81 (2010).

[3] P. Novák, T. Popela, J. Kubásek, J. Šerák, D. Vojtěch, A. Michalcová, Powder Metall. 54, 50 (2011).

[4] P. Novák, patent application PV 2010-189.

[5] P. Novák, A. Michalcová, I. Marek, M. Mudrová, K. Saksl, J. Bednarčík, P. Zikmund, D. Vojtěch, Intermetallics 32, 127 (2013).

[6] P. Novák, L. Mejzlíková, A. Michalcová, J. Čapek, P. Beran, D. Vojtěch, Intermetallics 42, 85 (2013).

[7] Z.H. Zhang, Z.F. Liu, J.F. Lu, X.B. Shen, F.C. Wang, Y.D. Wang, Scr. Mater. 81, 56 (2014). 